\title{
Understanding contextual barriers, supports, and opportunities for physical activity among Mexican-origin children in Texas border colonias: A descriptive study
}

M Renée Umstattd Meyer ${ }^{1 *}$, Joseph R Sharkey ${ }^{2}$, Megan S Patterson ${ }^{1}$ and Wesley R Dean ${ }^{2}$

\begin{abstract}
Background: The increasing numbers of colonias along the U.S.-Mexico border are characterized by disproportionately poor families of Mexican-origin, limited access to resources and health services, and heightened risk for obesity and diabetes. Despite consistent evidence supporting physical activity (PA) in prevention of chronic diseases, many individuals of Mexican-origin, including children, fail to meet PA recommendations. Environmental influences on PA, founded in ecological and social cognitive perspectives, have not been examined among children living in colonias. The purpose of this study was to identify and better understand (1) household and neighborhood environmental PA resources/supports, (2) perceived barriers to engaging in PA, and (3) PA offerings, locations, and transportation characteristics for Mexican-origin children living in colonias.
\end{abstract}

Methods: Data for this study were collected by promotora-researchers (indigenous community health workers trained in research methods) using face-to-face interviews conducted in Spanish. The sample consists of 94 mother-child dyads from Texas border colonias in Hidalgo County. Interviews included questionnaire items addressing PA barriers, household and neighborhood environmental support assessments conducted with each dyad, and open-ended questions that were coded to identify availability and locations of PA opportunities and transportation options. Descriptive statistics were calculated and differences between genders, birth countries, and BMl categories of children were determined using chi-square tests.

Results: All children were of Mexican-origin. The most frequently reported barriers were unleashed dogs in the street, heat, bad weather, traffic, no streetlights, and no place like a park to exercise. Prominent locations for current PA included schools, home, and parks. Common PA options for children were exercise equipment, running, playing, and sports. Environmental assessments identified exercise equipment (bicycles/tricycles, balls, etc....), paved/good streets, yard/patio space, and social norms as the most frequent household or neighborhood resources within these colonias. Differences in PA barriers, options, and environmental resources for genders, birth countries, and BMI categories were detected.

Conclusions: This study suggests that PA environmental resources, barriers, and opportunities for colonias children are similar to previous studies and distinctively unique. As expected, built resources in these communities are limited and barriers exist; however, knowledge of PA opportunities and available PA resources within colonias households and neighborhoods offers insight to help guide future research, policy, and PA initiatives.

Keywords: Mexican-origin children, physical activity, colonias, promotora-researchers, environmental support.

\footnotetext{
* Correspondence: Renee_Umstattd@Baylor.edu

'Baylor University, Department of Health, Human Performance, and

Recreation, One Bear Place 97313, Waco, TX 76798, USA

Full list of author information is available at the end of the article
} 


\section{Background}

Obesity, diabetes, related health conditions, and associated health burden disproportionately affect underserved, marginalized populations.[1-3] While the role of physical activity in prevention of obesity, diabetes, and related chronic conditions is well established,[4,5] these same populations face greater disparity in access to health care and health promotion services, including physical activity facilities and programming.[5,6] One underserved population characterized by both disproportionate ethnicity-related and socioeconomic burden is Mexican-origin families residing in impoverished colonias in the Lower Rio Grande Valley along the TexasMexico border.[6,7] The Mexican-origin population is the fastest growing subpopulation in the U.S., with the majority of this population growth occurring among the growing number of colonias along the U.S. border with Mexico, especially in Texas, and in new-destination immigrant communities throughout the nation. $[8,9]$

Colonias (Spanish for neighborhood or community) are substandard residential areas that usually lack infrastructure, exist along the U.S.-Mexico border, and were originally developed from subdivided agricultural lands in response to a deficit in low-income housing.[6,10] Colonias are characterized by inadequate (sometimes unpaved) roads, variable types and conditions of housing ranging from trailers to self-built houses, and often lack safe water, sewer services, and electricity.[6,11,12] The U.S. Government has defined colonias in various government and water codes as economically distressed communities consisting of low or very-low income households based on the Federal poverty index, with inadequate water or waste water services, located at or near the U.S.-Mexico border area with an outer range stretching from 50-150 miles into the U.S.[12,13] To provide a visualization, colonias have been described as Third World areas even though they are located within the United States of America.[10] Over 2,500 colonias span the U.S.-Mexico border, with approximately 2,200 providing homes to more than 400,000 in Texas. Within Texas, over 860 colonias, with an estimated 156,132 residents, are located in Hidalgo County alone. Figure 1 identifies colonias along the Texas-Mexico border and Hidalgo County. In addition, the border population is growing at a rate nearly double that of the rest of Texas, most of which is occurring in colonias. [10] Approximately $97 \%$ of those residing in colonias are of Hispanic origin (2/3 U.S. born), with an estimated 37\% lacking spoken English proficiency.[14] The image in Figure 2 provides an example of typical colonia residences in the south Texas Lower Rio Grande Valley.

\section{Texas colonia residents}

It is well documented that obesity and diabetes rates are astoundingly high across the nation and are even greater for Mexican-Americans, who have an $87 \%$ greater chance of diabetes diagnosis as compared to non-Hispanic whites. Rates along the U.S.-Mexico border are often even more extreme.[5,15-19] Given this stark health disparity, diabetes was recently identified as the prevailing preventable health issue among colonias residents. [6] However, this health disparity is further accentuated when considering additional health and economic disparities. Relationships between diabetes and obesity/overweight, hypertension, and high cholesterol are supported,[20] for which MexicanAmerican adults and children are at escalated risk of diagnosis, especially those living in colonias and other new-destination immigrant communities.[5,16,18,21-23] Evidence also suggests these rates continue to increase disproportionately for the poorest in our nation, including Mexican-Americans.[7,18,19] Mexican-Americans residing in colonias along the Texas-Mexico border unfortunately epitomize this risk given their markedly low household income rates (estimated at $<\$ 834 /$ month), consistent designation of persistent poverty, and high unemployment rates (20-70\% as compared to $7 \%$ nationally).[6,24]

While residents of colonias face numerous health and economic disparities, it is important to focus and capitalize on the communities' cultural assets and wealth.[25-28] Cultural wealth demonstrated in minority communities like colonias include familial capital, $[29,30]$ meaning that kinship ties to extended family and neighbors allow residents to learn the importance of maintaining a healthy connection to the community and its resources, and social capital,[31] which are peer and other social contacts that can provide both instrumental and emotional support to navigate through society.[25] The cultural strengths of colonias are valuable when considering an ecological approach to behavior change.

\section{The Role of physical activity}

Epidemiological data suggest a heightened and serious health risk for the burgeoning colonia population. Evidence consistently supports a positive and significant relationship between physical activity participation and reduced risks for diabetes, obesity/overweight, hypertension, and high cholesterol across all people and age groups.[4,5] However, few Mexican-Americans and lowerincome Americans, including children, report engaging in physical activity at levels related with health benefits. [32,33] Of adult U.S. Hispanics, 57.9\% report not engaging in sufficient physical activity to experience health benefits. [32] Among Hispanic high school youth in 2009, only $39.3 \%$ reported participating in 60 minutes of physical activity on 5 or more of the previous days, as compared to $46.6 \%$ of the entire high school population and $54.6 \%$ of non-Hispanic white youth.[34] Based on the consistent relationship between physical activity participation and the prevention of diabetes and obesity, insight is urgently 


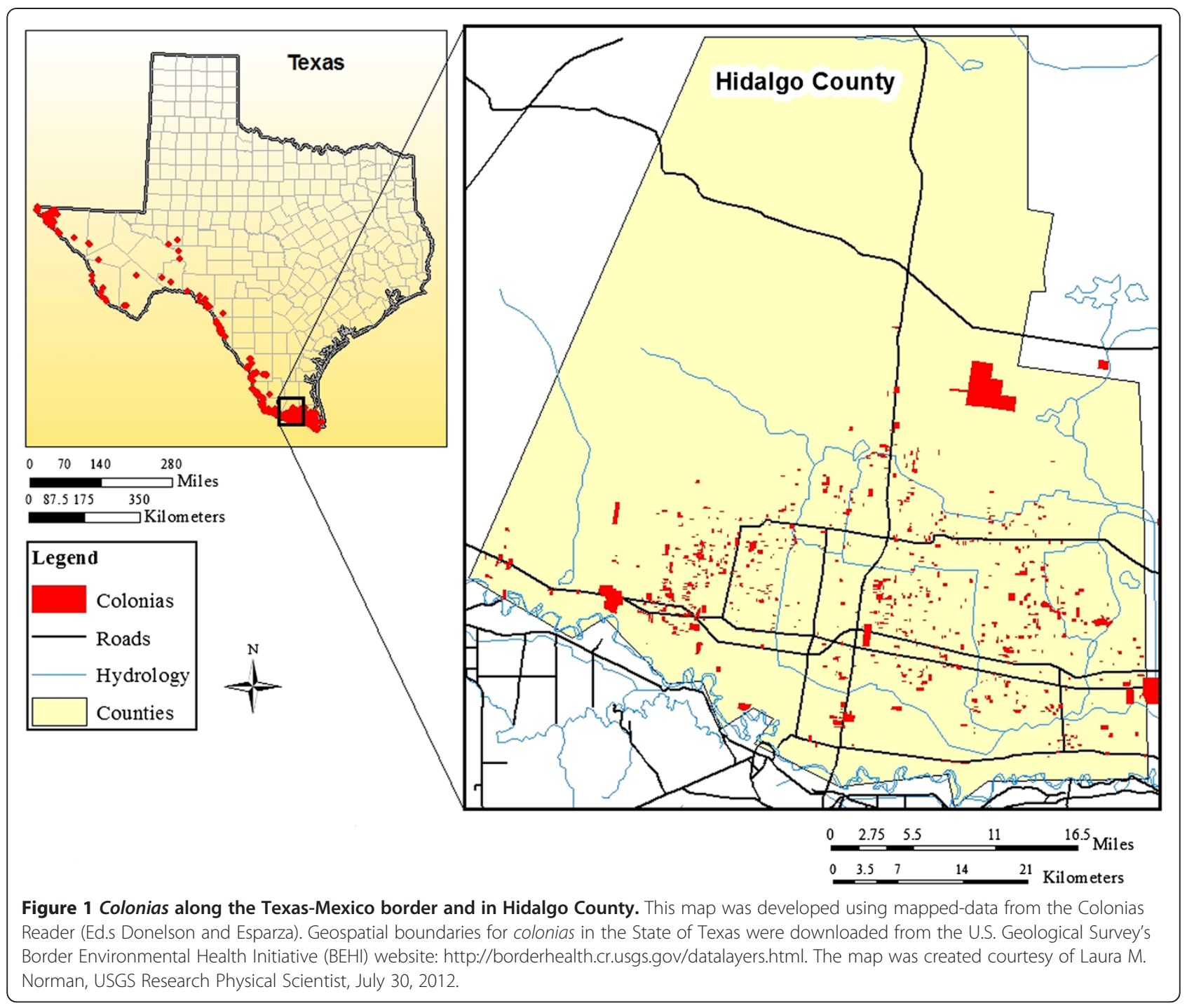

needed to better understand how to support and increase physical activity participation among this growing and disproportionately high risk population.

Environmental Influence: While substantial research exists examining intrapersonal-level factors that influence

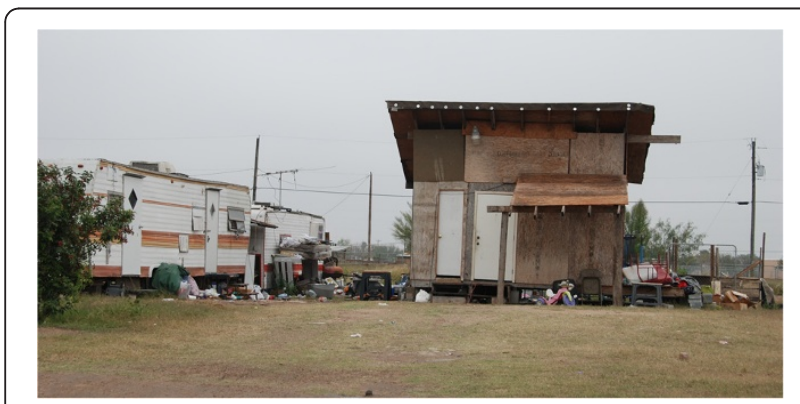

Figure $\mathbf{2}$ Colonia residences in Hidalgo County. Images were taken January 2011. physical activity, recently researchers have also begun to establish a strong evidence base regarding relationships between physical activity and the physical environment. $[35,36]$ Yet, as with other health issues, minorities, immigrant populations, and colonia residents in particular are rarely examined. $[6,37]$ Current evidence describes the influence of physical environmental features, such as street design, network connectivity, site design, density, safety, lighting, and aesthetic appeal of neighborhoods as important factors related with physical activity participation.[38] With the common absence of connectivity, playgrounds, parks, traditional yards, safe open spaces, and recreation facilities in colonias, physical activity could be severely limited as it is understood in urban-suburban and even rural literature, especially among youth.[6] However, these physical features and environmental concepts may not play significant roles, or may play distinctly unique roles in understanding physical activity participation among 
children residing in colonias.[6] Examining and understanding the physical environment in regards to physical activity engagement in colonia communities is vital to development of effective, efficient, and safe physical activity initiatives and policies for these underserved communities.

Two primary ways environmental influences are assessed are through objective measurement (audits/assessments/ observations) to capture the physical or built environment and self-report measures to understand perceived environmental supports and barriers.[39] Both concepts of environment, the actual physical environment and the perceived environment, are supported theoretically through ecological and social cognitive approaches. Ecological and social cognitive approaches are premised on multiple levels of reciprocal behavioral influence, where individual perceptions and beliefs are distinct, yet related and influenced by, the actual environment.[35,38,40,41] Given these theoretical pretenses, understanding both actual and perceived environmental factors is important, as either could facilitate or hinder physical activity participation.

Culturally-sensitive research, especially among hardto-reach populations, requires knowledge of the study population and trust of researchers by participants.[42] Research supports the importance of collaborating with trained promotoras who become trusted members of the research team while also serving as cultural brokers, having knowledge of the values, beliefs, and practices within Mexican-American households in the colonias. [43-45] Programs using community health workers (promotoras) have been some of the most successful in delivering primary and preventative health services and information in Mexican-American communities and specifically colonias.[6,45-49]

The purpose of this study was to identify and better understand (1) household and neighborhood environmental physical activity resources/supports, (2) perceived barriers to engaging in physical activity, and (3) physical activity offerings, locations, and transportation characteristics for Mexican-origin children living in $\mathrm{co}^{-}$ lonias. Given potential differences in physical activity participation and perceived barriers and environmental supports between female and male children, those children born in Mexico and the U.S., and children with different weight status, [50-54] a secondary aim of this study was to examine differences in physical activity resources and perceived barriers to physical activity between these groups.

\section{Methods}

Mother-child dyads $(n=94)$ were recruited by promotora-researchers (indigenous community health workers trained in research methods) to facilitate and partner within a project funded to examine food availability among Mexican American families in Texas colonias.
[11,55-57] Results from this study have been reported elsewhere.[11,55-57] Mother-child dyads consisted of a Mexican-origin mother and one of her children aged 6-11 who were living in colonias located in one of four large areas of colonias in Hidalgo County, Texas. These four areas were selected by team promotora-researchers based on prior research and outreach activities. Census block groups were used to spatially select 56 unique colonias, each varying in geography and population. Family dyads were subsequently recruited from these 56 colonias.

The present study used a mixed-methods approach, employing both quantitative and qualitative assessments. Measures were selected and refined during the winter of 2010 and spring of 2011 and data collection occurred during the spring of 2011. Interview items were designed to identify perceived household and neighborhood activity-supportive resources and environmental barriers pertaining to child physical activity, as well as current physical activity opportunities, locations, and transportation availability for colonias children. Environmental assessments were designed to identify activity-supportive resources within colonias households and neighborhoods. Promotora-researchers completed training in data collection and protection of participant confidentiality as provided by the project's investigators prior to data collection time periods. [57] Promotora-researchers also provided feedback regarding item wording, translation, understandability, and cultural appropriateness of all items. The trained promotora-researchers who were part of this research team are trusted by the colonia residents and served as cultural brokers, having knowledge of the values, beliefs, and practices within Mexican-American households in the colonias. All of the promotoraresearchers are native Spanish speakers and reside in area colonias. Interview completion was estimated to require a maximum of 20 minutes, a time determined as not burdensome in previous work with these families.

A team of two trained promotora-researchers conducted interviews with each mother-child dyad independently, where mothers and children were interviewed separately and had previously provided consent and assent to participate in the study. All interview responses were recorded by the promotora-researchers on paper and were then entered into a Microsoft Access database by a research assistant, where all data were double checked for accuracy. All materials and protocols were approved by the Texas A\&M University and Baylor University Institutional Review Boards.

Measures were translated into Spanish using a translation-back translation method: 1) translating original English into Spanish, ensuring the English meaning was maintained; 2) back-translating into English by an independent translator who was blinded and not familiar with either the Spanish or English version; 3) comparing 
the two English versions; and 4) resolving all discrepancies. Interviews were conducted in Spanish.

\section{Measures}

Physical activity neighborhood and household environmental support assessment items were guided and developed using current physical activity environmental literature, previously established environmental assessment instruments, and visual scans of 32 colonias conducted by the researchers in 3 areas of Hidalgo County in South Texas, which occurred in February 2011.[39,58-60] Visual scans provided the researchers with an overarching perspective regarding neighborhood and household environmental characteristics applicable for families residing in colonias. Promotora-researchers reviewed the resulting assessment items and 16 household and 23 neighborhood items were included. Each mother recorded which items existed in her home and immediate neighborhood.

Questionnaires conducted as face-to-face interviews by promotora-researchers also included demographic characteristics, health characteristics, barriers to physical activity for children, and open-ended items pertaining to (1) where children currently go to exercise, do physical activity, play sports, or play in a physically active manner; (2) what physical activity options are available for children to do physical activity, exercise, or sports; and (3) how children get to and from these physical activity locations.

Barrier items were developed using current physical activity literature, physical activity barrier scales, and feedback from promotora-researchers and included intrapersonal, interpersonal, and environmental barriers. [58,61,62] The final instrument included 28 items. Children were asked to identify which barriers "stop them from doing physical activity, exercise, or more exercise". Each mother was also asked to identify the barriers that prevent her son or daughter from engaging in exercise, physical activity or sport. Participants were instructed to select all that apply and an open-ended item concluded this portion of the interview allowing participants to include other potential barriers.

Demographic and health information was also obtained and included the following items for mothers and children separately: measured height and weight, general health status, age, gender (child only), birth country, age, number of children living at home (mothers), and household income (mothers). Height and weight were used to calculate body mass index (BMI) for both children and mothers $\left(\mathrm{BMI}=\right.$ weight $\left.(\mathrm{lbs}) /[\text { height }(\text { in })]^{2} \times 703\right)$, where mothers were considered overweight or obese with a BMI $\geq 25.0$ and children were considered overweight or obese with a BMI percentile $\geq 85^{\text {th }}$ percentile using the BMI-for-age percentile growth chart.[63-66] Health was assessed using a single item asking mothers and children separately to self-report their general health given 5 responses: poor, fair, good, very good, or excellent. Mothers and children were also asked to report her/his country of birth.

\section{Data analysis}

Descriptive statistics, including frequencies, means, and standard deviations were calculated to describe the demographic and health characteristics of the sample. Frequencies were also calculated to determine the most commonly reported environmental resources using data collected via the environmental assessments and barriers for childhood physical activity as perceived by colonias children and their mothers. Potential differences in barriers for boys and girls, countries of birth, and BMI categories, (1) under to normal weight and (2) overweight or obese, were examined using chi-square tests or fisher's exact test when estimated cell sizes were less than 5 . [67] Analyses were conducted using SPSS v19.

Analysis of open-ended questions followed a deductive approach tailored to identify physical activity opportunities and locations, and available transportation methods. A coding tree was developed based on previous literature within the areas of physical activity barriers, environmental support, rural settings, and Hispanic communities.[33,58,61,62] The coding tree was modified based on feedback from promotora-researchers and an initial review of interview responses to ensure saturation of themes. All data were coded independently by two primary coders. When a discrepancy in coding occurred, a third coder was incorporated and consensus was reached. Potential differences in opportunities and locations were examined for gender, birth country, and BMI category as described above.

\section{Results}

\section{Sample characteristics}

The average age of the children was 8.9 years $(\mathrm{SD}=1.5)$ and just over half were female $(58.5 \%, \mathrm{n}=55)$. All children and mothers were of Mexican-origin (100\%), where $73.4 \%$ of the children were born in the U.S. $(n=69)$. Eighty-seven percent of mothers were born in Mexico $(n=82)$. Just under half of the children were either overweight or obese using BMI percentiles $\left(48 \%, \mathrm{n}=45 ; \geq 85^{\text {th }}\right.$ percentile) and 30 of the children were obese ( $\geq 95^{\text {th }}$ percentile). Mean BMI percentile for the children was the $68^{\text {th }}(\mathrm{SD}=32.8)$ and $12 \%$ were either underweight $\left(<5^{\text {th }}\right.$ percentile, $\left.n=5\right)$ or at risk for being underweight $\left(5^{\text {th }}-15^{\text {th }}\right.$ percentile, $\mathrm{n}=6)$. Mean BMI percentile for children born in Mexico was $62^{\text {nd }}(S D=31.6), 70^{\text {th }}(\mathrm{SD}=33.3)$ for children born in the U.S., $65^{\text {th }}$ for female children, and $71^{\text {st }}$ for male children. T-tests revealed no significant differences when comparing either set of groups, although greater proportions of male children (53.8\%) and children born in the U.S. (52.2\%) were overweight or obese as compared to female children (43.6\%) and children born in Mexico (36.0\%). Eighty-four percent of mothers $(n=79)$ were either 
overweight or obese (BMI $\geq 25)$, where 12 were normal weight, $21 \%(\mathrm{n}=20)$ were overweight, $32 \%(\mathrm{n}=30)$ were obese class I $(\mathrm{BMI}=30.0-34.99), 18 \%(\mathrm{n}=17)$ were obese class II (BMI $=35.0-39.99)$, and $13 \%(\mathrm{n}=12)$ were obese class III (BMI $\geq 40.0$ ).[64] Nineteen (20.2\%) mothers reported their health as very good to excellent, with the majority reporting their health as fair or good $(n=68$, 72.3\%). Thirty-seven (39.4\%) children reported their health as very good to excellent, with the majority reporting their health as fair or good $(n=56,59.6 \%)$. The majority of these children have two married parents, and the majority of families (79\%) have 3 or more children living at home. More than half of these families had a total household income less than $\$ 699$ per month, with $96 \%$ of the families reporting a total household income less than $\$ 1,500$ per month.

\section{Household and neighborhood environmental resources and supports}

Environmental support assessments were completed by each mother pertaining to her household and neighborhood (see Table 1). The mean number of household environmental supports for physical activity was 5.2 (possible range: 0 to $16, \mathrm{SD}=2.5$ ). The mean number of neighborhood environmental supports for physical activity was 12.3 (possible range: -2 to $21, \mathrm{SD}=3.6$ ), where graffiti and traffic were negatively coded as these hinder activity versus support it. The following physical activity resources were limited in surveyed neighborhoods: recreational buildings $(24.5 \%)$ and walking tracks or trails (24.5\%). Additionally, neighborhoods frequently had the following characteristics shown to hinder physical activity participation: no stoplights (69.1\%), traffic (63.8\%), and "a lot of graffiti" (47.9\%). No significant differences were detected in household or neighborhood environmental assessment items when considering the child's gender or birth country.

Chi-square analyses examining differences in household and neighborhood resources and supports for normal weight versus overweight-obese children revealed significant differences for the following neighborhood resources: blocks available for walking, soccer fields, volleyball nets, and pools. Children with a normal BMI classification were more likely to have soccer fields within their neighborhood (63.3\%) than overweight or obese children $\left(37.8 \%, x^{2}=6.10, d f=1, p=.014\right)$. Children with overweight or obese BMI classification were more likely to have blocks for walking $\left(68.9 \%, \chi^{2}=4.62, \mathrm{df}=1\right.$, $\mathrm{p}=.032)$, volleyball nets $\left(42.2 \%, \mathrm{X}^{2}=7.683, \mathrm{df}=1, \mathrm{p}=.006\right)$, and pools $\left(75.6 \%, x^{2}=6.04, \mathrm{df}=1, \mathrm{p}=.014\right)$ within their neighborhoods than children with normal BMI classifications $(46.9 \%, 16.3 \%, 51.0 \%)$. No other significant differences in household or neighborhood resources or supports were detected between BMI classifications.
Table 1 Environmental assessment: Frequencies for household and neighborhood items $(n=94)$

\begin{tabular}{|c|c|c|}
\hline Assessment Item & $\begin{array}{l}\text { Household } \\
\text { Items: } \mathrm{n}(\%)\end{array}$ & $\begin{array}{l}\text { Neighborhood } \\
\text { Items: } \mathbf{n}(\%)\end{array}$ \\
\hline Trampoline & $21(22.3 \%)$ & $86(91.5 \%)$ \\
\hline Weight/exercise machine & $16(17.0 \%)$ & \\
\hline Balls (basket, soccer, football) & $75(79.8 \%)$ & $83(88.3 \%)$ \\
\hline $\begin{array}{l}\text { Basketball hoop/ } \\
\text { Functionality }\end{array}$ & $\begin{array}{l}26(27.7 \%) / \\
11(11.7 \%)\end{array}$ & $\begin{array}{l}79(84.0 \%) / \\
56(59.6 \%)\end{array}$ \\
\hline Bicycles and/or tricycles & $69(73.4 \%)$ & $91(96.8 \%)$ \\
\hline Swing set & $17(18.1 \%)$ & $82(87.2 \%)$ \\
\hline Scooter & $30(31.9 \%)$ & \\
\hline Volleyball net & $3(3.2 \%)$ & $27(28.7 \%)$ \\
\hline Wagon & $14(14.9 \%)$ & \\
\hline Tire swing & $7(7.4 \%)$ & \\
\hline $\begin{array}{l}\text { Tires for children to roll or play } \\
\text { with }\end{array}$ & $9(9.6 \%)$ & $24(25.5 \%)$ \\
\hline Push car & $48(51.1 \%)$ & \\
\hline $\begin{array}{l}\text { Non-motorized toy car } \\
\text { (pedal with feet) }\end{array}$ & $34(36.2 \%)$ & \\
\hline Yard or outdoor patio space & $86(91.5 \%)$ & $81(86.2 \%)$ \\
\hline Paved driveway & $14(14.9 \%)$ & \\
\hline $\begin{array}{l}\text { Swimming pool suitable } \\
\text { for swimming }\end{array}$ & $19(20.2 \%)$ & $59(62.8 \%)$ \\
\hline A block for walking & & $54(57.4 \%)$ \\
\hline Soccer field (formal or informal) & & $48(51.1 \%)$ \\
\hline $\begin{array}{l}\text { Children playing with balls in } \\
\text { streets }\end{array}$ & & $86(91.5 \%)$ \\
\hline $\begin{array}{l}\text { Good streets for walking or } \\
\text { running }\end{array}$ & & 77 (81.9\%) \\
\hline Walking track or trail & & $23(24.5 \%)$ \\
\hline $\begin{array}{l}\text { Park (in or right next to the } \\
\text { colonia) }\end{array}$ & & $48(51.1 \%)$ \\
\hline Open space like a field & & $39(41.5 \%)$ \\
\hline Paved streets & & $86(91.5 \%)$ \\
\hline $\begin{array}{l}\text { Children playing games } \\
\text { (hide \& seek/tag) }\end{array}$ & & $72(76.6 \%)$ \\
\hline $\begin{array}{l}\text { Recreational building of any type } \\
\text { (in or right next to the colonia) }\end{array}$ & & $23(24.5 \%)$ \\
\hline $\begin{array}{l}\text { Playground (schools or churches); } \\
\text { in or right next to the colonia }\end{array}$ & & $66(70.2 \%)$ \\
\hline Traffic & & $60(63.8 \%)$ \\
\hline Traffic lights & & $29(30.9 \%)$ \\
\hline Lots of graffiti in community & & $45(47.9 \%)$ \\
\hline
\end{tabular}

\section{Perceived barriers to physical activity}

Barriers to children's physical activity, exercise, or sport reported by children and their mothers were assessed (see Table 2). Subsequently, potential differences in perceived barriers to physical activity, exercise, or sport for boys and girls were examined. The only significantly different $(\mathrm{p} \leq .05)$ barrier for girls and boys reported by children was unleashed dogs in the street $\left(\chi^{2}=3.77, \mathrm{df}=1\right.$, 
Table 2 Physical activity barriers for colonias children reported by mother-child dyads: Examining gender differences

\begin{tabular}{|c|c|c|c|c|c|c|}
\hline \multirow[t]{3}{*}{ Barriers } & \multirow{2}{*}{\multicolumn{2}{|c|}{$\begin{array}{c}\text { Entire Sample } \\
(n=94)\end{array}$}} & \multicolumn{4}{|c|}{ Gender } \\
\hline & & & \multicolumn{2}{|c|}{ Boys $(n=39)$} & \multicolumn{2}{|c|}{ Girls $(n=55)$} \\
\hline & Child & Mother & Child & Mother & Child & Mother \\
\hline Transportation & $25.5 \%$ & $30.9 \%$ & $23.1 \%$ & $33.3 \%$ & $27.3 \%$ & $29.1 \%$ \\
\hline Dogs in street ${ }^{* C h}$ & $74.5 \%$ & $79.8 \%$ & $64.1 \%$ & $79.5 \%$ & $81.8 \%$ & $80.0 \%$ \\
\hline Lack of energy & $34.0 \%$ & $14.9 \%$ & $35.9 \%$ & $15.4 \%$ & $32.7 \%$ & $14.5 \%$ \\
\hline Traffic & $43.6 \%$ & $40.4 \%$ & $41.0 \%$ & $35.9 \%$ & $45.5 \%$ & $43.6 \%$ \\
\hline Crime & $13.8 \%$ & $25.5 \%$ & $12.8 \%$ & $23.1 \%$ & $14.5 \%$ & $27.3 \%$ \\
\hline No motivation & $38.3 \%$ & $13.8 \%$ & $48.7 \%$ & $15.4 \%$ & $30.9 \%$ & $12.7 \%$ \\
\hline No place like a park & $41.5 \%$ & $38.3 \%$ & $35.9 \%$ & $38.5 \%$ & $45.5 \%$ & $38.2 \%$ \\
\hline No one to do PA with & $25.5 \%$ & $17.0 \%$ & $28.2 \%$ & $23.1 \%$ & $23.6 \%$ & $12.7 \%$ \\
\hline Immigration status & $1.1 \%$ & $2.1 \%$ & $0.0 \%$ & $5.1 \%$ & $1.8 \%$ & $0.0 \%$ \\
\hline Kidnappings & $16.0 \%$ & $23.4 \%$ & $15.4 \%$ & $20.5 \%$ & $16.4 \%$ & $25.5 \%$ \\
\hline Time $^{* M}$ & $30.9 \%$ & $25.5 \%$ & $33.3 \%$ & $38.5 \%$ & $29.1 \%$ & $16.4 \%$ \\
\hline Small children at home & $1.1 \%$ & $3.2 \%$ & $2.6 \%$ & $0.0 \%$ & $0.0 \%$ & $5.5 \%$ \\
\hline No adequate clothing & $24.5 \%$ & $42.6 \%$ & $28.2 \%$ & $38.5 \%$ & $21.8 \%$ & $45.5 \%$ \\
\hline Can't leave house alone & $1.1 \%$ & $3.2 \%$ & $0.0 \%$ & $0.0 \%$ & $1.8 \%$ & $5.5 \%$ \\
\hline No sidewalks & $29.8 \%$ & $48.9 \%$ & $38.5 \%$ & $43.6 \%$ & $23.6 \%$ & $52.7 \%$ \\
\hline Trash & $12.8 \%$ & $21.3 \%$ & $17.9 \%$ & $28.2 \%$ & $9.1 \%$ & $16.4 \%$ \\
\hline No place to do PA & $34.0 \%$ & $35.1 \%$ & $33.3 \%$ & $35.9 \%$ & $34.5 \%$ & $34.5 \%$ \\
\hline No fenced area & $35.1 \%$ & $38.3 \%$ & $28.2 \%$ & $41.0 \%$ & $40.0 \%$ & $36.4 \%$ \\
\hline No streetlights & $44.7 \%$ & $55.3 \%$ & $46.2 \%$ & $53.8 \%$ & $43.6 \%$ & $56.4 \%$ \\
\hline Chickens/hens & $2.1 \%$ & $3.2 \%$ & $2.6 \%$ & $5.1 \%$ & $1.8 \%$ & $1.8 \%$ \\
\hline Gang activity & $23.4 \%$ & $30.9 \%$ & $28.2 \%$ & $33.3 \%$ & $20.0 \%$ & $29.1 \%$ \\
\hline Cows or goats & $2.1 \%$ & $1.1 \%$ & $0.0 \%$ & $2.6 \%$ & $3.6 \%$ & $0.0 \%$ \\
\hline Afraid child will get hurt & $20.2 \%$ & $20.2 \%$ & $20.5 \%$ & $25.6 \%$ & $20.0 \%$ & $16.4 \%$ \\
\hline No friends/family encourage PA & $21.3 \%$ & $6.4 \%$ & $23.1 \%$ & $10.3 \%$ & $20.0 \%$ & $3.6 \%$ \\
\hline PA is not fun & $14.9 \%$ & $2.1 \%$ & $20.5 \%$ & $5.1 \%$ & $10.9 \%$ & $0.0 \%$ \\
\hline Asthma & $6.4 \%$ & $7.4 \%$ & $5.1 \%$ & $7.7 \%$ & $7.3 \%$ & $7.3 \%$ \\
\hline Too hot & $55.3 \%$ & $51.1 \%$ & $61.5 \%$ & $51.3 \%$ & $50.9 \%$ & $50.9 \%$ \\
\hline Bad weather & $51.1 \%$ & $45.7 \%$ & $59.0 \%$ & $41.0 \%$ & $45.5 \%$ & $49.1 \%$ \\
\hline
\end{tabular}

$\mathrm{p}=.05)$, where more girls $(81.8 \%)$ perceived dogs in the street to be a barrier to physical activity as compared to boys (64.1\%). The only significantly different barrier to physical activity, exercise, or sport for boys and girls as reported by their mothers was time $\left(\chi^{2}=5.86, \mathrm{df}=1\right.$, $\mathrm{p}=.01$ ), where mothers more frequently reported time as a barrier to physical activity for boys (38.4\%) than girls (16.4\%). Barriers for boys and girls as reported by children and their mothers are presented in Table 2 .

Perceived barriers to physical activity, exercise, or sport for children were also examined for potential differences between children born in Mexico and the United States. Two perceived barriers to being active as reported by children significantly differed by birth country: lack of energy $\left(\mathrm{x}^{2}=7.37, \mathrm{df}=1, \mathrm{p}=.007\right)$ and transportation $\left(\mathrm{x}^{2}=3.75, \mathrm{df}=1, \mathrm{p}=.05\right)$. More children born in the U.S. reported "not having energy" as a barrier to being active (42.0\%) as compared to children born in Mexico (12.0\%), and more children born in Mexico reported transportation as a barrier to being active $(40.0 \%)$ as compared to children born in the U.S. (20.3\%). Perceived barriers to being active reported by mothers significantly differed by birth country for two barriers: immigration status $\left(x^{2}=5.64, \mathrm{df}=1, \mathrm{p}=.018\right)$ and kidnappings $\left(x^{2}=10.407, \mathrm{df}=1, \mathrm{p}=.001\right.$; see Table 3$)$. More children born in Mexico had a mother that reported immigration status as a barrier to her child being active $(8 \%)$ as compared to children born in the U.S. (0\%), and more children born in the U.S. had a mother that reported kidnappings as a barrier to her child being active $(31.9 \%)$ as compared to mothers whose child was born in Mexico (0\%). Barriers for children born 
Table 3 Physical activity barriers for colonias children reported by mother-child dyads: Examining differences by birth country

\begin{tabular}{|c|c|c|c|c|}
\hline \multirow[t]{3}{*}{ Barriers } & \multicolumn{4}{|c|}{ Birth Country } \\
\hline & \multicolumn{2}{|c|}{ Mexico $(n=25)$} & \multicolumn{2}{|c|}{ U.S. $(n=69)$} \\
\hline & Child & Mother & Child & Mother \\
\hline Transportation ${ }^{* C h}$ & $40.0 \%$ & $24.0 \%$ & $20.3 \%$ & $33.3 \%$ \\
\hline Dogs in street & $72.0 \%$ & $80.0 \%$ & $75.4 \%$ & $79.7 \%$ \\
\hline Lack of energy ${ }^{* C h}$ & $12.0 \%$ & $12.0 \%$ & $42.0 \%$ & $15.9 \%$ \\
\hline Traffic & $44.0 \%$ & $36.0 \%$ & $43.5 \%$ & $42.0 \%$ \\
\hline Crime & $20.0 \%$ & $12.0 \%$ & $11.6 \%$ & $30.4 \%$ \\
\hline No motivation & $28.0 \%$ & $16.0 \%$ & $42.0 \%$ & $13.0 \%$ \\
\hline No place like a park & $36.0 \%$ & $44.0 \%$ & $43.5 \%$ & $36.2 \%$ \\
\hline No one to do PA with & $32.0 \%$ & $24.0 \%$ & $23.2 \%$ & $14.5 \%$ \\
\hline Immigration status ${ }^{* M}$ & $0.0 \%$ & $8.0 \%$ & $1.4 \%$ & $0.0 \%$ \\
\hline Kidnappings $^{* M}$ & $20.0 \%$ & $0.0 \%$ & $14.5 \%$ & $31.9 \%$ \\
\hline Time & $24.0 \%$ & $20.0 \%$ & $33.3 \%$ & $27.5 \%$ \\
\hline Small children at home & $4.0 \%$ & $4.0 \%$ & $0.0 \%$ & $2.9 \%$ \\
\hline No adequate clothing & $32.0 \%$ & $44.0 \%$ & $21.7 \%$ & $42.0 \%$ \\
\hline Can't leave house alone & $0.0 \%$ & $0.0 \%$ & $1.4 \%$ & $4.3 \%$ \\
\hline No sidewalks & $40.0 \%$ & $44.0 \%$ & $26.1 \%$ & $50.7 \%$ \\
\hline Trash & $20.0 \%$ & $20.0 \%$ & $10.1 \%$ & $21.7 \%$ \\
\hline No place to do PA & $40.0 \%$ & $44.0 \%$ & $31.9 \%$ & $31.9 \%$ \\
\hline No fenced area & $40.0 \%$ & $44.0 \%$ & $33.3 \%$ & $36.2 \%$ \\
\hline No streetlights & $44.0 \%$ & $44.0 \%$ & $44.9 \%$ & $59.4 \%$ \\
\hline Chickens/hens & $4.0 \%$ & $0.0 \%$ & $1.4 \%$ & $4.3 \%$ \\
\hline Gang activity & $32.0 \%$ & $36.0 \%$ & $20.3 \%$ & $29.0 \%$ \\
\hline Cows or goats & $4.0 \%$ & $0.0 \%$ & $1.4 \%$ & $1.4 \%$ \\
\hline Afraid child will get hurt & $20.0 \%$ & $20.0 \%$ & $20.3 \%$ & $20.3 \%$ \\
\hline No friends/family encourage PA & $24.0 \%$ & $8.0 \%$ & $20.3 \%$ & $5.8 \%$ \\
\hline PA is not fun & $16.0 \%$ & $4.0 \%$ & $14.5 \%$ & $1.4 \%$ \\
\hline Asthma & $0.0 \%$ & $4.0 \%$ & $8.7 \%$ & $8.7 \%$ \\
\hline Too hot & $56.0 \%$ & $40.0 \%$ & $55.1 \%$ & $55.1 \%$ \\
\hline Bad weather & $52.0 \%$ & $40.0 \%$ & $50.7 \%$ & $47.8 \%$ \\
\hline
\end{tabular}

Notes. Bold = statistically significant $(\mathrm{p} \leq .05)$ difference between birth countries; ${ }^{* C h}=$ statistically significant difference in barrier for child report; ${ }^{* M}$ $=$ statistically significant difference in barrier for mother report; $\mathrm{PA}=$ physical activity, exercise, sport.

in Mexico and the U.S. as reported by children and their mothers are presented in Table 3.

Chi-square analyses examining differences in barriers to physical activity for normal weight versus overweightobese children revealed significant differences for transportation, traffic, and crime as reported by children, and transportation as reported by mothers. Children with a normal BMI classification were more likely (38.8\%) to report transportation as a barrier to physical activity than children with an overweight or obese BMI classification $\left(11.5 \%, \mathrm{x}^{2}=9.44, \mathrm{df}=1, \mathrm{p}=.002\right)$. Mothers of children with normal BMI classification were more likely
(40.8\%) to report transportation as a barrier to physical activity than mothers with children who had an overweight or obese BMI classification $\left(20.0 \%, \chi^{2}=4.76, \mathrm{df}=1\right.$, $\mathrm{p}=.029$ ). Children with normal BMI classification were also more likely to report traffic $\left(53.1 \% ; \chi^{2}=3.71, \mathrm{df}=1\right.$, $\mathrm{p}=.054)$ and crime (20.4\%; $\left.\mathrm{x}^{2}=3.72, \mathrm{df}=1, \mathrm{p}=.054\right)$ as barriers than children with overweight or obese BMI classifications (33.3\%; 6.7\%). No other significant differences between BMI classifications were detected.

\section{Physical activity offerings, locations, and transportation characteristics}

Salient themes were identified from open-ended responses describing where colonias children currently go to exercise, play sports, or play in a physically active manner as reported by the children and their mothers. Schools were the most frequently reported locations for current physical activities by children (75.5\%) and mothers (73.4\%), which included school grounds, physical education, and school gyms. Physical education at schools was specifically reported by $12.8 \%$ of the children and $11.7 \%$ of mothers. The home-area was the second most prominent location for current physical activity $(40.4 \%$ children, $36.2 \%$ mothers) and involved any physical activities occurring within the home, yard, or patio space, and included yard work and recreational activities. Of the children, 18.1\% reported parks, 9.6\% neighborhood, 5.3\% activities with others, and 3.2\% reported open fields/lots, sports, walking, and no physical activity. Of the mothers, $25.5 \%$ reported parks, $11.7 \%$ neighborhood, $8.5 \%$ playing, $4.3 \%$ exercise equipment, and $3.2 \%$ biking. Location codes with a frequency of $\leq 2$ for both children and mothers included other homes, running, church, strength activities, cardio activities, and community facilities. No significant differences for locations of current physical activities were detected between genders or birth countries. However, mothers of children with an overweight or obese BMI classification were more likely to report exercise equipment (8.9\%) than mothers of children with a normal BMI classification $\left(0 \%, \mathrm{X}^{2}=4.55, \mathrm{df}=1, \mathrm{p}=.033\right.$, fisher's exact test $\left.=.049\right)$.

Salient themes identified from the open-ended question inquiring about available physical activity options and opportunities for these children as reported by the children and their mothers were examined. The most frequently reported physical activity opportunities for children were using exercise equipment $(67.0 \%$ children, $59.6 \%$ mothers), which included balls, bikes, trampolines, monkey bars, etc. When a ball was mentioned in relation to a sport itself, the response was double-coded to capture the equipment and the sport. When biking was mentioned, it was double-coded to capture both biking and the equipment. Running (children: 62.8\%, mothers: $53.2 \%)$, playing $(50.0 \%, 41.5 \%)$, sports $(26.6 \%$, $21.3 \%)$, and biking $(18.1 \%, 24.5 \%)$ were the next most 
commonly reported opportunities reported by both the children and their mothers. Of the children, $17.0 \%$ reported cardiovascular activities, $12.8 \%$ walking, $8.5 \%$ activities at home, 5.3\% activities at a park, 5.3\% strength activities, $4.3 \%$ activities at school, and $3.2 \%$ activities with pets and activities at a community facility. Of the mothers, $18.1 \%$ reported walking, $14.9 \%$ cardiovascular activities, $10.6 \%$ activities at a park, $8.5 \%$ activities at school, $6.4 \%$ none, $4.3 \%$ activities at home and activities with music, and $3.2 \%$ activities in neighborhood. Opportunity codes with a frequency of $\leq 2$ for both children and mothers were activities with others, activities at church, in an open field or lot, and swimming.

Significant differences for birth country, gender, and BMI classification for physical activity opportunities were detected. More boys (38.5\%) than girls (18.2\%) reported "sports" ( $\left.\chi^{2}=4.807, \mathrm{df}=1, \mathrm{p}=.028\right)$. Similarly, more mothers of boy children (41.0\%) reported "sports" as a physical activity opportunity as compared to mothers of girls $(9.1 \%$; $\left.\mathrm{X}^{2}=13.413, \mathrm{df}=1, \mathrm{p} \leq .0001\right)$. More children born in Mexico (32\%) reported biking as a physical activity opportunity as compared to children born in the U.S. $\left(13 \%, \chi^{2}=4.45\right.$, $\mathrm{df}=1, \mathrm{p}=.035)$. Overweight or obese children (20.0\%) and mothers of these children (28.9\%) were more likely to report walking as an opportunity as compared to children with a normal BMI classification $\left(6.1 \%, \chi^{2}=4.06, \mathrm{df}=1\right.$, $\mathrm{p}=.044)$ and their mothers $\left(8.2 \%, \chi^{2}=6.80, \mathrm{df}=1, \mathrm{p}=.009\right)$. Normal weight children (10.2\%) were more likely to report strength training activities as opportunities as compared to overweight or obese children $\left(0 \%, x^{2}=4.85, \mathrm{df}=1\right.$, $\mathrm{p}=.028$, fisher's exact test $=.057)$. No other significant differences between groups were detected for children or mothers' responses.

When the children were asked where physical activity opportunities were located, $31 \%$ said they were at a school, 25\% said their home (house, patio, yard, etc....), $14 \%$ said a park (various city parks were mentioned), and $8 \%$ said in their neighborhood (the streets outside of home, in the colonia or neighborhood). Forty-four percent said these were located within their same town, 7\% said a neighboring town within 5 miles, $12 \%$ said a neighboring town 5-10 miles away, and only one person said a town 10-15 miles away. When asked how they get to and from the physical activity opportunities, $47 \%$ of the children stated they use the school bus for transportation to physical activity options, $45 \%$ are driven in a car, and $20 \%$ said they walk. No children mentioned using any type of public transportation or cycling. Three-fourths of these children's mothers owned a car and $60 \%$ of them reported having a car available to them during the day. Alternative forms of transportation included relatives (41\%) and family friends (20\%); although, $54 \%$ of mothers said they are charged to use these alternative forms of transportation.

\section{Discussion}

This study furthers our understanding of the physical activity environment for high-risk, underserved Mexicanorigin mothers and children living in Texas border colonias by describing (1) household and neighborhood infrastructure for physical activity, (2) perceived barriers to physical activity for these children, taking into account potential gender and birth country differences, and (3) physical activity opportunities and locations. Specifically, environmental support was assessed using items derived from current literature and previously developed environmental audits for rural and urban settings.[39,58-60] Given the uniqueness of colonia areas as compared to both urban and rural areas, it was imperative to tailor environmental support items to be culturally relevant and specific. In these assessments, several environmental factors consistently supportive of physical activity and health in previous research were reported. These included paved streets, streets deemed good for walking or running,[68] playgrounds (church or school) near the colonias, $[69,70]$ and supportive social norms of play via active children in the neighborhood (children playing with balls in the street and children playing games in neighborhood).[71] These assessments also revealed several environmental traits unsupportive of physical activity within colonias households and neighborhoods that are consistent with previous research and often more salient for low-income children. These included few recreation buildings[72,73] and traffic lights,[74,75] limited parks and open spaces (fields),[74] and high levels of traffic [73,76] and graffiti.[72,77]

Environmental characteristics unique to colonias were also identified in this study, including a high occurrence of yard and/or patio space and exercise equipment (e.g., balls, bicycles/tricycles, etc....). Although relationships between yard presence and/or yard size and exercise equipment with physical activity are not always supported in the literature,[71,78,79] the home area, including yards and patios, was reported as the second most common location for physical activity among participating children. While many colonia houses are on relatively generous lots, often fenced or walled-in, the houses themselves are usually built piece-by-piece as the family can afford to do so (also referred to as self-built or incremental construction), usually providing limited space for active recreational endeavors indoors.[10,24] In addition, several neighborhood barriers to physical activity were highlighted within this study, including unleashed dogs and traffic for all children and kidnappings for U.S.born children. These distinct contextual characteristics provide insight into why confining children to the homespace or yard could be perceived as safe and more supportive of physical activity. This explanation also provides insight into another potential household environmental 
barrier to physical activity distinct for colonias children, as relatively few driveways were paved (15\%). While paved driveways are not usually included as physical activity resources in the literature, given the context of colonia housing and neighborhood barriers, paved driveways could provide an additional home-based physical activity resource for children. Future research should investigate benefits and safety issues around paved driveways as a potential physical activity resource among less developed and unincorporated areas.

Items representing perceived barriers, both environmental and individual-level, were also derived from current literature and tailored for cultural relevance. As with the environmental assessment, interview responses highlighted barriers that are both unique to this population and similar to those within other samples. Unleashed dogs in the colonia streets was the predominant barrier to children being physically active for the sample as reported by both children and their mothers, regardless of gender or birth country. While the intensity of this finding is somewhat distinct to the colonias population as compared with other literature, unleashed dogs have been reported as relevant barriers to physical activity for other populations living in communities with potentially less infrastructure and development, such as rural U.S. areas, and for some international adolescents.[77,80,81] These findings support the need to identify whether unleashed dogs are an actual or perceived environmental barrier to physical activity. Future initiatives should address the perceived barrier of unleashed dogs within these neighborhoods and educate on dog protection. Additionally, initiatives need to acknowledge the intensity of this perception/fear, while also investigating actual safety threats of unleashed dogs, as incongruence between perceptions and actual threats would suggest different intervention foci. Regardless, initiatives encouraging physical activity of colonias children, especially girls, should address this barrier with children themselves and their mothers.

Traffic, lack of street lights, and bad weather/heat are other environmental barriers prominent in this study previously identified for children and other underserved communities.[62,76,80,82,83] Although heat is somewhat unavoidable during most of the year in south Texas, future education and programming should address risks associated with heat. Concerns about traffic and lack of streetlights should be communicated to policy makers and non-governmental organizations to help increase advocacy for change and inform about infrastructure and zoning needs. One challenge to making environmental changes is the fact that many colonias are not within local governance, but rather within countylevel governance. Advocacy efforts should occur at the local, county, and state-level, and communication across all levels is essential.
Several group differences detected in this study highlight unique considerations when encouraging physical activity among colonias children. Time was reported by mothers as a significantly more prominent barrier to physical activity for boys in comparison (39\%) to girls (16\%). While time is not the predominant barrier for boys in this study, this difference is worth examining and is consistent with previous research reporting time and other priorities (work, school, family) as barriers to physical activity for Hispanic adolescent boys.[83] Because low income families are more likely to rely on children for household chores and babysitting, [84] boys' perception of free time available for physical activity could decrease. In addition, mothers and fathers tend to lack the time to supervise or provide transportation at the appropriate times for boy's physical activities, notably sports participation.[85] Boys participate in sports activities significantly more often than girls,[86] thus linking less time available for boys to participate in their reported physical activities than their female counterparts. Another potential explanation of this gender difference can be seen through the lens of Hispanic adult males where differences between the American culture and the culture of their countries of origin have been identified as barriers to physical activity. Specifically, in the American culture Hispanic men reported having less time available and fewer social activities involving physical activity (e.g., soccer) as compared to their home country's culture.[83] This difference could also be important for Hispanic boys, suggesting that time should be considered as a barrier when planning physical activity initiatives that include Mexican-origin boys. Future research should also further examine this finding.

Four differences in barriers were also detected when comparing children born in different countries. Children born in Mexico were more likely to report lack of transportation as a barrier to physical activity (42\%) than children born in the U.S. (20\%), even with no significant differences between car ownership or availability during the day and mother's employment (part/full-time versus not working or full-time versus part-time/not working) for mothers of children born in Mexico (car ownership: $75 \%$, car availability: $50 \%$, any work: $10 \%$, full-time: $10 \%$ ) as compared to the U.S. (car ownership: $81 \%$, car availability: 65\%, any work: 24\%, full-time: 6\%). Physical activity initiatives targeting children residing in colonias should take this into account, as up to $1 / 3$ of colonias residents are born in Mexico.[14]

Children born in the U.S. were more likely to report a lack of energy $(42 \%, n=29)$ as a barrier as compared to children born in Mexico (12\%, $n=3)$. Although the subsample of children born in Mexico is modest, this difference is notable. While lack of energy, feeling tired, or fatigue has been inversely related with physical activity 
and positively related with sedentary time among adult populations, $[62,83,87]$ it is not usually examined as a potential barrier of physical activity for children[71,83,88] and distinctions between first and second generation Mexican-origin children have not been examined. However, food insecurity is related with fatigue among other health risks and obesity for children, where children of low income families and specifically colonias families are at greater risk for food insecurity.[56,89] Although our findings do not clearly support the explanation or provide insight into why American-born versus Mexican-origin children were more likely to report energy as a barrier to physical activity, $96 \%$ of the study population has a monthly income $<\$ 1,500$, suggesting all families in this study have a heightened risk for food insecurity. The risk for food insecurity and associated fatigue is even greater when considering all Mexican-born children and approximately half of U.S.-born children reporting "lack of energy" as a barrier came from families making $<\$ 700$ per month. Another potential explanation could exist when considering the south Texas climate. Given extreme high temperatures and many families lacking air conditioning, a lack of energy could be explained given the heat and potential dehydration. In considering this potential explanation and the high frequency of participants reporting heat as a barrier to physical activity in this study, physical activity initiatives must take into account the environmental element of heat.

Differences seen between normal weight children and those who were overweight-to-obese suggest cultural preferences and support metabolic understandings. $[4,90]$ Given that children with normal BMIs were more likely to have soccer fields available in their neighborhoods and report strength training as an available physical activity opportunity than overweight/obese children suggests that normal weight children either have more resources supportive of vigorous and strength activities, both related with greater metabolic expenditure than light-to-moderate activity,[4] or are more likely to be aware of these resources as compared to overweight-toobese children. This is also supported when considering that overweight-to-obese children were more likely to have blocks for walking and report walking as an available physical activity opportunity than normal weight children. Future research needs to understand whether there is a lack of resources or an incongruence between perceptions and availability. Outcomes of this assessment would inform the direction of future initiatives. The greater reports of soccer fields within neighborhoods of children with normal BMIs also lends insight into how these children might be or could overcome their reported barriers of transportation, traffic, and crime; as they would be able to walk to soccer fields within their neighborhoods and would most likely be associated with larger groups of people while there, which could reduce perceptions of fear.

Locations of current physical activities and available physical activity opportunities emphasize the importance of school and home environments and supportive physical activity resources and modes including exercise equipment, running, playing, sports, and biking. Although most physical activity opportunities reported are located within a relatively short distance from the areas that the children live (usually in the child's "home town" or a neighboring town of the colonia in which they reside), only $20 \%$ of these children reported walking as a form of transportation to these locations. In addition, this supports both the need for school-based physical activity opportunities that incorporate transportation and the importance of home-based physical activity options. These findings substantiate previous studies that suggest the greatest opportunity for lower income children to engage in physical activity is within the school setting, as school-based physical activity has demonstrated an equalizing effect for socio-economic status differences associated with physical activity.[91-93] These results also support the continued call for physical education programs and free-play/recess during the school day and the utilization of school transportation options within after-school programming to allow for additional physical activity opportunities and engagement within highrisk, underserved populations.[92-95]

Parks and churches are also environmental structures that support physical activity.[69,70,96] However, a limited number of parks are documented within or near the colonias. With $42 \%$ of children reporting a barrier of "no place like a park," and research supporting the relationship between parks and playgrounds with physical activity for children, physical activity programming for children living near parks and future policies for colonias-area planning to include more park spaces and/or playgrounds should be considered.[70,96] Additionally, future research needs to further examine the quality and availability of playground and park features in colonias, as some research suggests it is not simply the presence of a park or playground that is related to physical activity, but rather the features and quality of the facilities. $[97,98]$ In this study, one child and one mother reported a church as a location for physical activity. Given the strong religious heritage of the Mexican culture,[99,100] churches could potentially support physical activity of colonias residents. In addition, previously reported relationships between church facilities and physical activity for adolescents, including rural and minority youth, [69] support future research aimed at examining the current role and future potential of churches within colonias communities in regards to policies and programming related with physical activity. 
The use of mixed-methods and mother-child dyads to examine environmental supports, barriers, and locations of physical activity are strengths of this study design, in addition to the examination of differences by gender and birth country. Another strength lies in the tailoring of environmental measures (assessment and barriers), as these items were both based on previously used measures and culturally tailored for relevance and specificity to this distinct population. However, given this approach, validity and reliability of these measures is not established. Additionally, although these results provide a rich description of the physical activity environment for children residing in south Texas colonias, causality was not examined. While future studies should seek to validate these measures in similar colonias and new-immigrant populations and examine causal relationships, current research supports the need to describe the environmental landscape and understand environmental factors of physical activity and obesity to inform physical activity and obesity-prevention policies and initiatives, especially among our highest risk and underserved populations.

\section{Conclusions}

While this study focuses on children residing in colonias within the Texas-Mexico border region, these findings should be used to inform future research, policy, and public health initiatives for other colonias communities along the U.S.-Mexico border and rapidly growing newimmigrant destination communities seen throughout America. While immigrants in the past century have primarily settled in one of a few gate-way urban cores, more recent trends evidence an increase of newimmigrant destinations throughout rural and less-settled urban-periphery counties found across the U.S., including the Midwest and Southeast among others. $[9,101]$ Recent immigration trends reveal approximately half of immigrants residing in urban areas and $2 / 3$ of immigrants in rural areas are Hispanic, where $48 \%$ of rural immigrants are of Mexican-descent.[9] Given most Hispanic and specifically Mexican immigrants are faced with similar challenges as colonias residents regardless of geographical location, including severe poverty, educational disadvantages, escalated risk for chronic diseases, underemployment, and residences within ethnic enclaves,[9] colonias can serve as an archetypal example for researchers, public health practitioners, and policy makers in understanding these new-immigrant destinations scattered across the nation.

Future research should aim to understand the social environment of children residing in colonias, in addition to school and church-based policies, programming, and infrastructure as they relate to physical activity support. Future physical activity initiatives targeting colonias children should incorporate a community-based participatory research (CBPR) approach working with community promotoras and consider programs incorporating currently available exercise equipment, while developing physical activity initiatives within schools, homes, and parks that incorporate transportation for children. Policy makers should use these findings to help guide decisions about resource allocation within colonias and new-destination immigrant communities to increase parks, playgrounds, and access to school grounds. This study suggests that environmental resources and barriers for colonias children are both similar to previous studies and distinctively unique. As expected, built resources for these communities are limited; however, knowledge of barriers and available physical activity resources within colonia households and neighborhoods offers insight and can help guide policy and physical activity initiatives. Future work should also focus on facilitating neighborhood groups and linkages with non-governmental organizations to increase advocacy for community change.

\section{Competing interests}

The authors declare that they have no competing interests.

\section{Authors' contributions}

MRUM contributed to the conception of this study, analysis and interpretation of the data, and drafted the manuscript. JRS contributed to the conception and design of the study, acquisition of data, and critically revised the manuscript. MSP contributed to the analysis and interpretation of data and critically revised the manuscript. WRD contributed to the design of the study and critically revised the manuscript. All authors have given final approval of the manuscript for publication.

\section{Acknowledgements}

We gratefully acknowledge the participants of this study, whose time and willingness made this project possible. We also thank the promotoraresearchers whose continual efforts made this study possible, Esther Valdez, CHW; Thelma Aguillon, CHW; Mayte Garza, CHW; and Maria Davila Castillo, $\mathrm{CHW}$. Additionally, we thank the following research assistants who were involved with various elements of this project: Garrett Sansom, MPH and Courtney Nalty, MSPH with the Texas A\&M Program for Research in Nutrition and Health Disparities, and Cindy L. Salazar, BA and Samantha J. Allen, BS with the Department of Health, Human Performance and Recreation at Baylor University. This project was supported through several funding mechanisms that we would like to acknowledge: RWJF/Healthy Eating Research \#66969, NIH/NIMHD \#5P20MD002295, and the CDC/Cooperative Agreement \#1U48DP001924 Core Research Project and Special Interest Project Nutrition and Obesity Policy Research and Evaluation Network.

\section{Author details}

'Baylor University, Department of Health, Human Performance, and Recreation, One Bear Place 97313, Waco, TX 76798, USA. ²Program for Research in Nutrition and Health Disparities, Department of Health Promotion and Community Health Sciences, Texas A\&M School of Rural Public Health, TAMU1266, College StationTX 77843-1266, USA.

Received: 24 August 2012 Accepted: 6 January 2013

Published: 8 January 2013

\section{References}

1. Cowie CC, Rust KF, Byrd-Holt DD, Eberhardt MS, Flegal KM, Engelgau MM, Saydeh SH, Williams DE, Geiss LS, Gregg EW: Prevalence of diabetes and impaired fasting glucose in adults in the U.S. population: National health and nutrition examination survey 1999-2002. Diabetes Care 2006, 29(6):1263-1268. 
2. Gregg EW, Cheng YJ, Narayan KM, Thompson TJ, Williamson DF: The relative contributions of different levels of overweight and obesity to the increased prevalence of diabetes in the United States: 1976-2004. Preventive Medicine 2007, 45(5):348-352.

3. Ogden CL, Carroll MD, Curtin LR, McDowell MA, Tabak CJ, Flegal KM: Prevalence of overweight and obesity in the United States, 1999-2004. JAMA 2006, 295(13):1549-1555.

4. Physical Activity Guidelines Advisory Committee: Physical Activity Guidelines Advisory Committee Report, 2008. In. Washington, DC: U.S: Department of Health and Human Services; 2008.

5. U.S. Department of Health and Human Services (USDHHS): Healthy People 2020. In. Washington, DC: U.S. Government Printing Office: U.S: Department of Health and Human Services; 2010.

6. Donelson AJ, Esparza AX: The colonias reader: Economy, housing, and public health in U.S.-Mexico border colonias. Tuscon, AZ: The University of Arizona Press: Donelson AJ, Esparza AX; 2010.

7. Fisher-Hoch SP, Rentfro AR, Wilson JG, Salinas JJ, Reininger BM, Restrepo BI, McCormick JB, Perez A, Brown HS, Hossain MM, et al: Socioeconomic status and prevalence of obesity and diabetes in a Mexican American community, Cameron County, Texas, 2004-2007. Preventing Chronic Disease 2006, 7(3):1-10.

8. Humes KR, Jones NA, Ramirez RR: Overview of race and Hispanic origin: 2010. In.: U. S. Census Bureau: Humes KR, Jones NA, Ramirez RR; 2011.

9. Jensen L: New immigrant settlements in rural America: Problems, prospects, and policies. Carsey Institute, University of New Hampshire: In: Reports on rural America. vol. 1. Durham, New Hampshire; 2006.

10. Ward PM: Colonias and public policy in Texas and Mexico: Urbanization by stealth. Austin, TX: University of Texas Press; 1999

11. Dean WR, Sharkey JR, Johnson CM, St John J: Cultural repertoires and food-related household technology within Colonia households under conditions of material hardship. International Journal for Equity in Health 2012, 25.

12. Abbot G: Colonias prevention. Texas AGo: In. Edited by; 2011.

13. Texas border and Mexican affairs: What is a colonia?. In. Edited by State TSO; 2012.

14. Power JG, Byrd T: U.S.-Mexico border health. Thousand Oaks, CA: SAGE Publications: Issues for regional and migrant populations; 1998.

15. Mier N, Medina AA, Ory MG: Mexican Americans with type 2 diabetes: Perspectives on definitions, motivators, and programs of physical activity. Preventing Chronic Disease 2007, 4(2).

16. United States-Mexico Border Area: In: Health in the Americas, 2007. Pan American Health Organization (PAHO): Volume ii, edn; 2007:732-744.

17. Centers for Disease Control and Prevention (CDC): National diabetes fact sheet: national estimates and general information on diabetes and prediabetes in the United States, 2011. Centers for Disease Control and Prevention: In. Atlanta, GA: U.S. Department of Health and Human Services; 2011.

18. Flegal KM, Ogden CL, Carroll MD: Prevalence and trends in overweight in Mexican-American adults and children. Nutr Rev 2004, 64(2):S9-S14.

19. Umpierrez GE, Gonzalez A, Umpierrez D, Pimental D: Diabetes mellitus in the Hispanic/Latino population: An increasing health care challenge in the United States. American Journal of Medical Science 2007, 334(4):274-282.

20. Centers for Disease Control and Prevention (CDC) Division of Diabetes Translation: Percentage of risk factors for complications among adults with diabetes, United States, 2007. Department of Health and Human Services, Centers for Disease Control and Prevention: Behavioral Risk Factor Surveillance System. In. Atlanta, GA: U.S; 2009.

21. Mier N, Ory MG, Zhan D, Conkling M, Sharkey JR, Burdine JN: Health-related quality of life among Mexican Americans living in colonias in the TexasMexico border. Soc Sci Med 2008, 66:1760-1771.

22. Flegal KM, Carroll MD, Ogden CL, Curtin LR: Prevalence and trends in obesity among US adults, 1999-2008. JAMA 2010, 303(3):235-241.

23. Ogden CL, Carroll MD, Curtin LR, Lamb MM, Flegal KM: Prevalence of high body mass index in US children and adolescents, 2007-2008. JAMA 2010, 303(3):242-249.

24. Federal Reserve Bank of Dallas: Texas colonias.: A thumbnail sketch of the conditions, issues, challenges and opportunities. In; 1995.

25. Yosso TJ: Whose culture has capital? A critical race theory discussion of community cultural wealth. Race Ethnicity and Education 2005, 8(1):69-91.

26. Solorzano D, Solorzano R: The Chicano educational experience: A proposed framework for effective schools in Chicano communities. Educational Policy 1995, 9:293-314.
27. Valencia R, Solorzano D: Contemporary deficit thinking. In: The evolution of deficit thinking in educational thought and practice. New York: Falmer Press: edn. Edited by Valencia R; 1997:160-210.

28. Villalpando O, Solorzano D, In: Preparing for college: Nine elements of effective outreach: The role of culture in college preparation programs: A review of the literature. NY: SUNY Press: edn. Edited by Tierney W, Corwin Z, Kolyar J. Albancy; 2005:13-28.

29. Delgado Bernal D: Using a Chicana feminist epistemology in educational research. Harvard Educational Review 1998, 68(4):555-582.

30. Delgado Bernal D: Critical race theory, LatCrit theory and critical racedgendered epistemologies: Recognizing students of color as holders and creators of knowledge. Qualitative Inquiry 2002, 8(1):105-126.

31. Stanton-Salazar RD: Manufacturing hope and despair: The school and kin support networks of US-Mexican youth. New York: Teachers College Press; 2001.

32. Centers for Disease Control and Prevention (CDC): Behavioral Risk Factor Surveillance System Survey Data. In. Atlanta, GA: U.S: Department of Health and Human Services, Centers for Disease Control and Prevention; 2007.

33. Parks SE, Housemann RA, Brownson RC: Differential correlates of physical activity in urban and rural adults of various socioeconomic backgrounds in the United States. J Epidemiol Community Health 2003, 57:29-35.

34. Centers for Disease Control and Prevention (CDC): Youth Risk Behavior Surveillance System (YRBSS) survey data. Department of Health and Human Services, Centers for Disease Control and Prevention; 2009.

35. Sallis JF, Glanz K: Physical activity and food environments: Solutions to the obesity epidemic. Milbank Q 2009, 87(1):123-154.

36. McNeill LH, Kreuter MW, Subramanian SV: Social environment and physical activity: A review of concepts and evidence. Soc Sci Med 2006, 63:1011-1022.

37. Kumanyika SK: Environmental influences on childhood obesity: Ethnic and cultural influences in context. Physiol Behav 2008, 94:61-70.

38. Sallis JF, Cervero RB, Ascher W, Henderson KA, Kraft MK, Kerr J: An ecological approach to creating active living communities. Annual Review of Public Health 2006, 27:297-322

39. Sallis JF: Measuring physical activity environments: A brief history. American Journal of Preventive Medicine 2009, 36(4S):S86-S92.

40. Bandura A: Social foundations of thought and action: A social cognitive theory. Englewood Cliffs, NJ: Prentice-Hall; 1986.

41. Glanz K, Rimer BK, Viswanath K: Health behavior and health education. San Francisco, CA: Jossey-Bass: Theory, research, and practice, 4th edn; 2008.

42. Cassidy CM: Walk a mile in my shoes: Culturally sensitive food-habit research. Am J Clin Nutr 1994, 59(Suppl):190S-197S.

43. Johnson CM, Sharkey JR, Dean WR: It's all about the children: a participant-driven photo-elicitation study of Mexican-origin mothers' food choices. BMC Women's Health 2011, 11(41).

44. Johnson CM, Sharkey JR, Dean WR, St John JA, Castillo MJ: Promotoras as research partners to engage health disparity communities. Journal of the Academy of Nutrition and Dietetics in press,

45. John JA, Johnson CM, Sharkey JR, Dean WR, Arandia G: Empowerment: evolution of promotoras as promotora-researchers in the Comidas Saludables \& Gente Sana en las Colonias del Sur de Tejas (Healthy Food and Healthy People in South Texas Colonias) Program. Journal of Primary Prevention in press

46. Arvey SR, Fernandez ME, LaRue DM, Bartholomew LK: When promotoras and technology meet: A qualitative analysis of promotoras' use of small media to increase cancer screening among South Texas Latinos. Health Educ Behav 2012, 39(3):352-363.

47. Blanco CE: Promotoras: A culturally sensitive intervention for Hispanic breastfeeding women. Journal of Obstetric, Gynecologic and Neonatal Nursing 2011, 40(19)

48. Ontiniano AD, Carroll-Scott A, Toy P, Wallace SP: Supporting Latino communities' natural helpers: A case study of promotoras in a research capacity bulding course. Journal of Immigrant Minority Health 2012, 14:657-663.

49. Getrich C, Heying S, Willging C, Waitzkin H: An ethnography of clinic "noise" in a community-based, promotora-centered mental health intervention. Soc Sci Med 2007, 65(2):319-330.

50. Evenson KR, Sarmiento OL, Ayala GX: Acculturation and physical activity among North Carolina Latina immigrants. Soc Sci Med 2004, 59:2509-2522.

51. Hazuda HP, Haffnew SM, Stern MP, Eifler CW: Effects of acculturation and socioeconomic status on obesity and diabetes in Mexican Americans: The San Antonio heart study. Am J Epidemio/ 1988, 128(6):1289-1301. 
52. McKenzie TL, Sallis JF, Nader PR, Broyles SL, Nelson JA: Anglo- and Mexican American preschoolers at home and at recess: Activity patterns and environmental influences. J Dev Behav Pediatr 1992, 13(3):173-180.

53. Trost SG, Pate RR, Sallis JF, Freedson PS, Taylor WC, Dowda M, Sirard J: Age and gender differences in objectively measured physical activity in youth. Medicine \& Science in Sports \& Exercise 2002, 2012(2):350-355.

54. Duncan MJ, Birch S, Woodfield L, Al-Nakeeb Y: Perceptions of the built environment in relation to physical activity and weight status in British adolescents from central England. ISRN Obesity 2012, 2012.

55. Sharkey JR, Dean WR, St John JA, Huber JC: Using direct observations on multiple occasions to measure household food availability among lowincome Mexicano residents in Texas colonias. BMC Public Health 2010, 10(445).

56. Sharkey JR, Dean WR, Johnson CM: Association of household and community characteristics with adult and child food insecurity among Mexican-origin households in colonias along the Texas-Mexico border. International Journal for Equity in Health 2011, 10(19).

57. Sharkey JR, Nalty C, Johnson CM, Dean WR: Children's very low food security is associated with increased dietary intakes in energy, fat, and added sugar among Mexican-origin children (6-11 y) in Texas border colonias. BMC Pediatrics 2012, 12(16).

58. Brownson RC, Baker EA, Housemann RA, Brennan LK, Bacak SJ: Environmental and policy determinants of physical activity in the United States. Am J Public Health Nations Health 2001, 91(12):1995-2003.

59. Umstattd MR, Baller SL, Hennessy E, Hartley D, Economos CD, Hyatt RR, Yousefian A, Hallam JS: Development of the Rural Active-Living Perceived Environmental Support Scale (RALPESS). Journal of Physical Activity and Health 2012, 9(5):724-730.

60. Yousefian A, Hennessy E, Umstattd MR, Economos CD, Hallam JS, Hyatt RR, Hartley D: Development of the rural active living assessment tools: Measuring rural environments. Preventive Medicine 2010, 50:S86-592.

61. Gordon-Larson P, Griffith P, Bentley ME, Ward DS, Kelsey K, Shields K, Ammerman A: Barriers to physical activity: Qualitative data on caregiverdaughter perceptions and practices. American Journal of Preventative Medicine 2004, 27(3):218-223.

62. Salmon J, Owen N, Crawford D, Bauman A, Sallis JF: Physical activity and sedentary behavior: A population-based study of barriers, enjoyment, and preference. Health Psychol 2003, 22(2):178-188.

63. BMI Percentile Calculator for Child and Teen: Results on a Growth Chart; [http://apps.nccd.cdc.gov/dnpmi/Calculator.aspx]

64. WHO, Report of a WHO Consultation. In: Obesity: preventing and managing the global epidemic. Geneva: World Health Organization: WHO Technical Report Series; 2000.

65. National Heart LaBl: Clincial guidelines on the identification, evaluation, and treatment of overweight and obesity in adults. National Institutes of Health: The evidence report. In; 1998.

66. Mei Z, Grummer-Strawn LM, Pietrobelli A, Goulding A, Goran MI, Dietz WH: Validity of body mass index compared with other body-composition screening indexes for the assessment of body fatness in children and adolescents. Am J Clin Nutr 2002, 75(6):978-985.

67. Agresti A: Categorical Data Analysis. 2nd edition. Hoboken, NJ: Wiley; 2002.

68. Sharpe PA, Granner ML, Hutto B, Ainsworth BE: Association of environmental factors to meeting physical activity recommendations in two South Carolina counties. American Journal of Health Promotion 2004, 18(3):251-257

69. Pfeiffer K, Colabianchi N, Dowda M, Porter D, Hibbert J, Pate RR: Examining the role of churches in adolescent girls' physical activity. Journal of Physical Activity \& Health 2011, 8:227-233.

70. Potwarka LR, Kaczynski AT, Flack AL: Places to play: Association of park space and facilities with healthy weight status among children. Journal of Community Health 2008, 33:344-350.

71. Veitch J, Salmon J, Ball K: Individual, social and physical environmental correlates of children's active free-play: A cross-sectional study. International Journal of Behavioral Nutrition and Physical Activity 2010, 7(11).

72. Sugiyama T, Leslie E, Giles-Corti B, Owen N: Physical activity for recreation or exercise on neighbourhood streets: Associations with perceived environmental attributes. Health \& Place 2009, 15:1058-1063.

73. Zhu $X$, Lee $C$ : Walkability and safety around elementary schools: Economic and ethnic disparities. American Journal of Preventive Medicine 2008, 34(4):282-290.
74. Timperio AF, Crawford D, Telford A, Salmon J: Perceptions about the local neighborhood and walking and cycling among children. Preventive Medicine 2004, 38:39-47.

75. Timperio AF, Ball K, Salmon J, Roberts R, Giles-Corti B, Simmons D, Baur LA Crawford D: Personal, family, social, and environmental correlates of active commuting to school. American Journal of Preventive Medicine 2006, 30(1):45-51.

76. Trapp GSA, Giles-Corti B, Christian HE, Bulsara M, Timperio AF, McCormack GR, Villaneuva KP: Increasing children's physical activity: individual, social, and environmental factors associated with walking to and from school. Health Educ Behav 2012, 39(2):172-182.

77. Carver A, Salmon J, Campbell K, Baur LA, Garnett S, Crawford D: How do perceptions of local neighborhood relate to adolescents' walking and cycling? American Journal of Health Promotion 2005, 20(2):139-147.

78. Trost SG, Pate RR, Saunders RP, Ward DS, Dowda M, Felton G: A prospective study of the determinants of physical activity in rural fifthgrade children. Preventive Medicine 1997, 26:257-263.

79. Trost SG, Pate RR, Ward DS, Saunders RP, Riner W: Determinants of physical activity in active and low-active, sixth grade African-American youth. Journal of School Health 1999, 69(1):29-34.

80. Hennessy E, Kraak VI, Hyatt RR, Bloom J, Fenton M, Wagoner C, Economos $\mathrm{CD}$ : Active living for rural children: Community perspectives using PhotoVOICE. American Journal of Preventive Medicine 2010, 39(6):537-545.

81. Sanderson B, Littleton M, Pulley L: Environmental, policy, and culturual factors related to physical activity among rural, African American women. Women Health 2002, 36(2):75-90.

82. Jago R, Baranowski J, Zakeri I, Harris M: Observed environmental features and the physical activity of adolescent males. American Journal of Preventive Medicine 2005, 29(2):98-104.

83. Bragg MA, Tucker CM, Kaye LB, Desmond F: Motivators of and barriers to engaging in physical activity: Perspectives of low-income culturally diverse adolescents and adults. American Journal of Health Education 2009, 40(3):146-154.

84. Romero AJ: Low-income neighborhood barriers and resources for adolescents' physical activity. J Adolesc Health 2005, 36(3):253-259.

85. Hsueh J, Yoshikawa $\mathrm{H}$ : Working nonstandard schedules and variable shifts in low-income families: Associations with parental psychological wellbeing, family functioning, and child well-being. Development Psychology 2007, 43(3):620-632.

86. Sallis JF, Zakarian JM, Hovell MF, Hofstetter R: Ethnic, socioeconomic, and sex differences in physical activity among adolescents. J Clin Epidemiol 1996, 49(2):125-134

87. Brownson RC, Baker EA, Housemann RA, Brennan LK, Bacak SJ: Environmental and policy determinants of physical activity in the United States. Am J Public Health 2001, 91(12):1995-2003.

88. van der Horst K, Paw MJCA, Twisk JWR, Mechelen W: A brief review on correlates of physical activity and sedentariness in youth. Medicine \& Science in Sports \& Exercise 2007, 39(8):1241-1250.

89. Casey PH, Szeto K, Lensing S, Bogle M, Weber J: Children in food-insufficient, low-income families. Arch Pediatr Adolesc Med 2001, 155:508-514.

90. Garcia R, Flores ES, Pine E: Dreams of fields: Soccer, community, and equal justice. In: Report on Sports in Urban Parks to the California Department of Parks and Recreation. Los Angeles: Center for Law in the Public Interest; 2002.

91. Kristjansdottir G, Vilhjalmsson R: Sociodemographic differences in patterns of sedentary and physically active behavior in older children and adolescents. Acta Paediatr 2001, 90:429-435.

92. Gordon-Larson P, McMurray RG, Popkin BM: Determinants of adolescent physical activity and inactivity patterns. Pediatrics 2000, 105(6).

93. Ferreira I, van der Horst K, Wendel-Vos W, Kremers S, van Lenthe FJ, Brug J: Environmental correlates of physical activity in review - a review and update. Obesity Reviews 2006, 8:129-154.

94. Pate RR, Davis MG, Robinson TN, Stone EJ, McKenzie TL, Young JC: Promoting physical activity in children and youth: A leadership role for schools: A scientific statement from the American Heart Association Council on Nutrition, Physical Activity, and Metabolism (Physical Activity Committee) in collaboration with the Councils on Cardiovascular Disease in the Young and Cardiovascular Nursing. Circulation 2006, 114:1214-1224.

95. Wechsler H, Devereaux RS, Davis M, Collins J: Using the school environment to promote physical activity and healthy eating. Preventive Medicine 2000, 31:S121-S137. 
96. Moody JS, Prochaska JJ, Sallis JF, McKenzie TL, Brown M, Conway TL: Viability of parks and recreation centers as sites for youth physical activity promotion. Health Promotion Practice 2004, 5(4):438-443.

97. Colabianchi N, Maslow AL, Swayampakala K: Features and amenities of school playgrounds: A direct observation study of utilization and physical activity levels outside of school time. International Journal of Behavioral Nutrition and Physical Activity 2011, 8(32).

98. Kaczynski AT, Potwarka LR, Saelens BE: Association of park size, distance, and features with physical activity in neighborhood parks. Am J Public Health 2008, 98:1451-1456.

99. Espinosa G, Garcia MT: Introduction. In: Mexican American religions: Spirituality, activism, and culture. NC: Duke University: edn. Edited by Espinosa G, Garcia MT. Durham; 2008:1-14.

100. Lujan JC, Campbell HB: The role of religion on the health practices of Mexican Americans. Journal of Religion and Health 2006, 45(2):183-195.

101. Kandel W, Cromartie J, In: Rural development research report: New patterns of Hispanic settlement in rural America. Washington, D.C: Department of Agriculture; 2004.

doi:10.1186/1471-2458-13-14

Cite this article as: Umstattd Meyer et al:: Understanding contextual barriers, supports, and opportunities for physical activity among Mexican-origin children in Texas border colonias: A descriptive study. BMC Public Health 2013 13:14.

\section{Submit your next manuscript to BioMed Central and take full advantage of:}

- Convenient online submission

- Thorough peer review

- No space constraints or color figure charges

- Immediate publication on acceptance

- Inclusion in PubMed, CAS, Scopus and Google Scholar

- Research which is freely available for redistribution 